\title{
Material de suturas en periodoncia e implantes.
}

\author{
Sutures, silk, periodontics, biocompatible materials, dental implantation
}

Johnny Canales $^{1, a}$, Carlos Espinoza-Montes ${ }^{1, b}$, Marco Alarcón-Palacios ${ }^{1, c}$

\section{RESUMEN}

Entre los biomateriales más usados en Periodoncia e Implantología Oral las suturas constituyen parte fundamental del éxito de los tratamientos quirúrgicos. En la extensa revisión de la literatura disponible no hay una idea clara del material ideal de sutura para la cirugía periodontal e implantológica. A pesar de varias evaluaciones comparativas que se han publicado existen controversias de las propiedades, la biodegradabilidad y el rendimiento de los materiales de sutura. El presente artículo propone revisar las propiedades de los materiales de suturas absorbibles y no absorbibles más utilizados en Periodoncia e Implantología Oral.

\section{Palabras Clave: SUTURAS, SEDA, PERIODONCIA, MATERIALES BIOCOMPATIBLES, IMPLANTACIÓN} DENTAL.

\begin{abstract}
Among the most widely used biomaterials in Periodontology and Oral Implantology sutures are part of the success of surgical treatments. In the extensive review of the available literature there is no clear idea ideal suture material for periodontal and implant surgery. Despite several benchmarks have been published there are controversies about the properties, biodegradability and performance of suture materials. This article proposes to revise the material properties of absorbable sutures and non-absorbable used in Periodontology and Oral Implantology.
\end{abstract}

Key Words: SUTURES, SILK, PERIODONTICS, BIOCOMPATIBLE MATERIALS, DENTAL IMPLANTATION

\footnotetext{
Facultad de Estomatología. Universidad Peruana Cayetano Heredia. Lima, Perú.

Estudiante de Maestría en Estomatología.

Magister en Estomatología.

Docente de la Especialidad de Periodoncia e Implantes.
} 


\section{INTRODUCCIÓN}

La importancia de conocer el tipo de material de sutura a utilizar, constituye una prioridad absoluta en cualquier procedimiento quirúrgico intra o extraoral. Los materiales de sutura se comportan como cuerpos extraños en el interior de la herida, induciendo una reacción inflamatoria, que de acuerdo con las características del hilo de sutura, puede terminar en la absorción o la eliminación al exterior. Si el número de estos cuerpos extraños es excesivo, la reacción inflamatoria puede afectar a la cicatrización de la herida, lo que puede propiciar la infección. Las suturas que se utilizan son de tipo absorbibles y no absorbibles 1 .

La reacción inflamatoria ante una sutura no absorbible es, en general, menos intensa frente a las absorbibles, siendo el orden decreciente de intensidad para la seda, algodón, poliéster, naylon, polipropilene y acero1. Si producen tensión de la herida, disminuyen la microcirculación y el aporte de oxígeno; por esta razón, es absolutamente necesario poseer un conocimiento profundo y detallado de las propiedades físicas, químicas y técnicas de los materiales de sutura. Si bien no existe un material adecuado para todas las situaciones quirúrgicas, algunos se comportan de mejor manera en diferentes heridas, por cuanto al momento de elegir algunos de éstos se debe considerar la resistencia, tipo y condición del tejido a suturar 1, 2 .

\section{REACCIÓN TISULAR}

Todo material de sutura se comporta como una sustancia extraña en el organismo y puede determinar una reacción tisular; el grado de esta reacción varía según el tipo de sutura. La secuencia normal de la reacción tisular tiene tres etapas: los primeros cuatro días, predominan los polinucleares, linfocitos y monocitos; a partir del séptimo día, aparecen los macrófagos y fibroblastos; y, después del séptimo día, persiste el tejido fibroso con inflamación crónica. Alrededor de las suturas no absorbibles se forma una cápsula fibrosa y la reacción inflamatoria es mínima; sin embargo, alrededor de las suturas absorbibles, la reacción persiste hasta que la misma es absorbida o eliminada. Los materiales orgánicos, como la seda y el catgut, son más reactivos que los sintéticos como el polipropileno 1, 2 .
El material de sutura debe permanecer en su lugar en un periodo prolongado produciéndose una interacción entre el material de sutura y los tejidos circundantes. 3 Tres días después de la colocación de una sutura, se observa una ligera invaginación del tejido epitelial a lo largo de la pared interior que delimita el hilo quirúrgico. Es mayor en el caso de seda que en los monofilamentos. En el tejido conectivo están presentes algunas células inflamatorias y células progenitoras de tejido de granulación. Siete días después se produce un ligero descarrillado de los filamentos individuales de la sutura trenzada acompañado de colonización bacteriana sobre todo en los intersticios de la estructura tridimensional del filamento.1 La epitelización del canal por el que discurre la sutura está casi completa. En oportunidades en la zona central puede haber tejido paraqueratosis y/o células inflamatorias. A los 14 días la parte más central está cubierta totalmente por epitelio y es claramente visible la doble capa de células queratinizada, sin márgenes celulares ni núcleos. La acumulación de bacterias entre las fibras trenzadas del hilo de sutura de seda, en gran medida, por bacterias con forma de bastón y fusiformes. El tejido de granulación con islas de neoangiogénesis reemplaza las zonas de células inflamatorias. Este cambio está en relación al tipo de hilo de sutura empleado y de la presencia o ausencia de tratamiento antibacteriano local o sistémico. La sutura en la encía queratinizada puede inducir respuesta inflamatoria alrededor de la sutura. La cantidad de epitelio que rodea la sutura, que recubre el canal tisular en contacto con el material de sutura, tiende a disminuir con el tiempo hasta la remoción de los puntos 1, 3, 4 .

\section{MATERIALES DE SUTURAS}

El material de sutura más utilizado es la seda negra no reabsorbible, la seda, natural, entrelazada o multifilamento torcido, cubierto con la cera o silicona para reducir la capilaridad, derivada del capullo del gusano de seda y constituido el $70 \%$ de proteínas naturales y el $30 \%$ por material extraño. Muchos fabricantes la impregnan y cubren con ceras y siliconas para reducir la capilaridad, para aumentar la impermeabilidad y la fluidez. Ofrece desventajas como la reacción del tejido, correlacionado con la anidación de bacterias en los filamentos intersticios, por lo cual se evita su empleo en heridas infectadas, no es lo suficientemente resistente, poco elástica y 
fluida. Por lo tanto, debido a su reacción inflamatoria, no es agradable su empleo en tejidos infectados. Entre las ventajas de su uso figuran la flexibilidad, un buen estado del nudo, maniobrabilidad y bajo costo $2,5,6,7$.

El ácido poliglicólico (PGA) es un polímero biodegradable, termoplástico y es el miembro más sencillo de la familia de los poliésteres alifáticos lineales. Puede ser sintetizado a través de la condensación o polimerización con la apertura del anillo de ácido glicólico. El PGA constituye multifilamento entrelazado y puede presentarse en sí mismo en una forma recubierta, revestidos y no. El recubrimiento permite obtener una estructura de pseudo-monofilamento que reduce la capilaridad, y aumenta el deslizamiento, sino que facilita la disolución del nudo. Presenta una reabsorción lenta, que comienza después de $10-15$ días, que se completará en 90 a 180 días. Las fibras del PGA se caracterizan por una elevada resistencia a la tracción, aproximadamente $7 \mathrm{GPa}$. Para obtener polímeros con características específicas, varios copolímeros PGA se prepararon utilizando otros monómeros 1,2, 6 .

El poliglactin 910 combina partes iguales de copolímero de láctido, glicólido y estearato de calcio en su recubrimiento. El resultado es un lubricante absorbible, adherente y no desprendible. Poseen paso fácil por el tejido, colocación precisa del nudo, suavidad al bajar el nudo y menor tendencia a encarcelar tejidos. A los 14 días posimplante, queda aproximadamente $65 \%$ de la fuerza de tensión y a los 21 días, $40 \%$ en las calibre 6-0 y mayores y $10 \%$ a los 35 días. La absorción es mínima hasta el día 40, y esencialmente es completa entre los días 56 y 70 por hidrólisis. Provocan solamente una leve reacción tisular durante su absorción. Se encuentra disponible en hilos trenzados teñidos de color violeta para aumentar su visibilidad en el tejido o sin teñir. Nombre comercial: Vicryl 5,6.

\section{ANTECEDENTES}

Wallance y Col. (1970) refieren que la reacción tisular a los materiales de sutura usados en la cavidad oral no ha sido estudiada, frecuentemente y basada en hechos reales aparece incompleta y a la vez complicado. Algunos estudios reportan que la seda causa mayor intensidad y prolongada respuesta inflamatoria gingival de la mucosa oral que los materiales sintéticos 8 .

Lilly y Col. (1972) observan que las suturas multifilamento producen gran reacción inflamatoria que los monofilamentos. El vicril y el polipropileno inducen menor reacción inflamatoria que la seda negra 9.

Postlethwait R. y Col. (1975) reportaron que las suturas sintéticas causan menos reacción inflamatoria que las suturas naturales 1.0.

Racey y Col. (1978) compararon la respuesta inflamatoria de la mucosa oral y las características mecánicas de tres materiales de sutura (hilo de seda, catgut crómico y el ácido poliglicólico). En este estudio se determinó que el ácido poliglicólico y la seda producían la misma inflamación luego de siete días de implantación, no se pudo comparar el catgut crómico por ser absorbido normalmente antes de este tiempo. Sin embargo cuando aún se encuentra presente, generalmente produce una reacción inflamatoria severa. Con respecto a las características mecánicas se concluyó que el ácido poliglicólico y la seda tienen características similares por ser trenzados 24 .

Varma y Col. (1981) observaron que la duración y la intensidad de la reacción inflamatoria varían de acuerdo al material usado, la técnica quirúrgica y el tejido en el cual se va suturar 25 .

Abi Rached y Col. (1991) realizaron un estudio en 36 pacientes para evaluar la reacción gingival a cuatro diferentes materiales de sutura usados en cirugía periodontal. La biopsia se realizó a los 3,7 y 14 días, al examen histológico se observó que la seda causaba más intensa y larga respuesta inflamatoria. El Polyester y el perlón provocaron menor reacción tisular y el nylon menor aún 11.

Okamoto (1994) realizó un estudio histomorfólogico comparativo efectuando suturas en mucosa oral de ratas con polyglactin 910 y ácido poliglicólico, tras la extracción de incisivos. Los resultados demostraron que las dos clases de materiales de sutura causan una reacción inflamatoria aguda de corta duración durante los primeros días. El ácido poliglicólico causó una 
mayor proliferación fibroblástica y capilar que el poliglactin 910, observándose un discreto retraso en la cicatrización alveolar con las suturas de poliglactin 910. En otro estudio, del mismo autor se encontró que la seda, en relación con el nylon y el poliéster, produjo una mayor reacción inflamatoria durante las primeras etapas, aunque fue menor que la del algodón 12.

Selvig y Col. (1998) refieren que la invasión bacteriana en el canal de sutura fue una secuela común, independientemente del material utilizado, pero fue particularmente importante para la seda. La formación de una cubierta epitelial perisutural estaba muy avanzada en 3 días y a los 7 días cubiertos completamente en algunos casos. A los 14 días, estas zonas fueron sustituidas en parte por tejido de granulación rodeado por una cápsula fibrosa. La sutura monofilamento sintético provocó una respuesta inflamatoria leve. Los resultados mostraron que las suturas colocadas en la encía y la mucosa oral producen una respuesta tisular prolongada, que es más probable un resultado de la afluencia continua de contaminación microbiana a lo largo del canal de sutura y que puede ser un problema menor cuando las suturas se colocan en otros compartimentos quirúrgicos. Una intensa respuesta inflamatoria al material de sutura y el trauma de su colocación es visible después de 3 días 13.

Nary (2002) obtuvo como resultado que el material de sutura polyglecaprone induce a una reacción inflamatoria leve, seguido de poliglactin 910 y politetrafluoretileno, respectivamente. Recomendó considerar el comportamiento biológico durante la selección del material de sutura a utilizar en cirugía oral 14.

Yaltirik y Col. (2003) en un estudio in vivo usaron 4 diferentes materiales de sutura (catgut, seda, polipropileno y vicril) en los tejidos blandos de 32 ratas, realizaron las incisiones suturadas por una técnica estándar. Los resultados demostraron que el vicril como material de sutura produjo la reacción tisular más leve durante el periodo de reparación temprana 15.

Leknes y Col. (2005) encontraron en sus resultados que la colocación de suturas en los tejidos gingivales provoca una reacción inflamatoria y que la magnitud de esta reacción puede variar con el material de sutura utilizado. Suturas de seda trenzada, aparentemente causa una reacción inflamatoria del tejido más amplio en un entorno caracterizado por la humedad y el potencial infeccioso 16 .

Leknes y Col. (2005) evaluaron las reacciones de los tejidos con sutura de seda y sutura de politetrafluoroetileno expandido (ePTFE) en la presencia y la ausencia de terapia antinfecciosa. Se concluyó que las suturas de seda resultaron más susceptibles para producir reacciones inflamatorias que las suturas de ePTFE 17.

Parirokh en el 2006, comparó el efecto de diferentes tiempos de retiro del material de sutura en la cicatrización de la herida quirúrgica. Utilizó 21 conejos albinos machos bajo anestesia general y local, un colgajo mucoperióstico rectangular fue levantado en cada uno de los animales y llevado a su sitio y suturados. Los animales fueron divididos aleatoriamente en tres grupos experimentales de siete animales cada uno. En el grupo I y II, las suturas se retiran después de 3 y 5 días En conclusión, en base al resultado de este estudio, 7 días fue reconocido con el mejor intervalo de tiempo para la retirada de la sutura en comparación con los otros dos intervalos de tiempo 18 .

Burkhardt R en el 2008, evaluó la influencia de la tensión del colgajo en las características desgarro de muestras de tejido de la mucosa en relación con la sutura de diversas características de agujas. Utilizó revestimiento y masticatorios muestras de tejidos obtenidos a partir de la mucosa mandíbulas de cerdo se prepararon para los ensayos in vitro 19.

Sortino y Col. (2008) encontraron que la reacción inflamatoria del tejido gingival es baja para el ácido poliglicólico comparado con la seda. Sin embargo las condiciones de la herida, evaluado a los 8 días después de la cirugía son aceptables en ambos hilos. 20

Mirković S (2010) La comparación de los parámetros citados de los materiales seda Negra Silcona 5-0, Nylon 5-0 y Vicryl 5-0. estudiados después de la sutura de la mucosa oral reveló que ninguno de los materiales utilizados era ideal, sin embargo, una cierta ventaja podría darse a los materiales de sutura de monofilamento sintéticos 21 .

Kim y Col.(2011) concluyó que los materiales de sutura colocados en la mucosa oral provocaron 
más reacciones inflamatorias que aquellos ubicados en la encía queratinizada. Los materiales de sutura multifilamento causaron más reacción inflamatorias que los materiales de sutura monofilamento en la mucosa oral 22.

Fawad y Col. (2012) concluyeron que las reacciones tisulares a los materiales de sutura utilizados para las intervenciones quirúrgicas orales pueden variar dependiendo de las propiedades superficiales de estos materiales y la adhesión bacteriana 23 .

\section{CONCLUSIONES}

Esta revisión se propone llevar a centrarse datos dispersos en la química, las propiedades, la biodegradabilidad y el rendimiento de las suturas absorbibles y no absorbibles. Las suturas están desarrollando nuevas todo el tiempo, para responder mejor a las necesidades particulares quirúrgicos. Materiales básicos se modifica en función de su aplicación destinada a proporcionar al cirujano un material de sutura decalidadóptima. Las características actuales usados de hilos biológicamente inertes, sintético, absorbible, no absorbible y han acercando al límite de los requisitos impuestos por la cirugía moderna. Para ello es necesario seguir avanzando en este ámbito, que se puede anticipar si los procesos de fabricación para la producción de hilo resistente y elástica hecha de polímeros biocompatibles absorbibles naturales - polyoxyalkanoates, colágeno, quitina, alginato, etc, son desarrollados. La atención de los investigadores se centra cada vez más en los materiales de sutura con potencial no sólo para la actividad antimicrobiana, pero también funciona anestésica y antineoplásica.

\section{CORRESPONDENCIA}

Canales Johnny G. Teléfono: 4590744-997161572

Calle los milanos 1285 urb. La Basilia S.J.L. Lima, Perú.

Correo electrónico: Johnny21_73@hotmail.com

\section{REFERENCIAS BIBLIOGRÁFICAS}

1. Siervo S, Técnicas de Sutura en Cirugía Oral. 1a ed.España. Quintessenz; 2008.

2. Vidarte G, Suturas Dermatología Peruana. Perú. 2001;11:7-12.
3. Cohen ES. Atlas of cosmetic and reconstructive periodontal surgery, 2nd ed. Philadelphia: Lea \& Febiger; 1994:9-30.

4. Knauf M, Kohal R. Material y técnicas de sutura en cirugía plástica periodontal. Quintessenz 2006;57(6):635-58.

5. Meyle J. Suture materials and suture technique .Quintessenz. 2006;3(4):253-68

6. Wound closure manual. Somerville, NJ: Ethicon. 1985:1-101

7. Tabanella G, Oral tissue reactions to suture materials: A review. J West Soc Periodontol 2004;52(2):37-44.

8. Wallace W, Maxwell GR, Cavalari C. Comparison Of polyglycolic acid suture to black silk, chromic, an plain catgut in human oral tissues. J Oral Surg. 1970:28:739-46.

9. Lilly GE, Cutcher J, Jones J, Armstrong J. Reaction of oral tissue to sutures materials. Oral Surg Oral Med Oral Pathol Oral Radiol \& Endod. 1972;33:152-7.

10.Postlethwait R., Willigan D. Human tissue reaction to suture Ann of Surg. 1975;181:144-50.

11.Racey G, Wallace W, Cavalaris C, Marquad J. Comparison of a polyglycolic- polylactic acid suture to black silk and plain catgut in human oral tissue. Oral Surg Oral Med Oral Pathol Oral Radiol \& Endod. 1978;36:766-70.

12.Okamoto T. Healing process of the gingival mucosa and dental alveolo following tooth extraction and suture with polyglycolic acid and polyglactin 910 threads. Comparative histomorphologic study in rats. Braz Dent J. 1994;5(1):35-43

13.Selvig K, Guy B, Knut L, Ulf W. Oral tissue reactions to suture materials.

Int J of Periodontol \& Rest Dent. 1998;18:475-87

14.Nary H, Matsumoto M, Batista A, Lopes L, Sampaio F, Consolaro A. Comparative study of tissue response to polyglecaprone 25, polyglactin 910 and polytetrafluorethylene suture materials in rats. Braz Dent J. 2002;13(2):86-91

15. Yaltirik M., Comparison of four different suture materials in soft tissues of rats. Oral Dis. 2003;9:284-6.

16.Leknes K, Human Gingival Tissue Reactions to Silk and Expanded polytetrafluoroethylene sutures. J of Clin Periodontol. 2005;76:34-42.

17.Leknes K, Selvig KA, et al Tissue reactions to sutures in the presence and absence of anti-infective therapy. $\mathrm{J}$ of Clin Periodontol. 2005;32:130-38.

18.Parirokh et al the effect of different suture removal time intervals on surgical wound healing. IEJ 2006; 1 (3)

19.Burkhardt R, Preiss A, Joss A, Lang NP. Influence of suture tension to the tearing characteristics of the soft tissues: an in vitro experiment. Clin. Oral Impl. Res. 19, 2008; 314-9

20.Sortino F, Lombardo C, Sciacca A. Silk and polyglycolic 
acid in oral surgery: A comparative study. Oral Surg, Oral Med Oral Pathol Oral Radiol \& Endod. 2008; 105 (3): 15-18.

21.Mirković S (2010) Influence of surgical sutures on wound healing. Med Pregl. 2010 Jan-Feb;63(1-2):7-14.
22.Kim J. et al. Tissue reactions to suture materials in the oral mucosa of beagle dogs .J Periodontal Implant Sci 2011; 41(4):185-191

23.Javed F, Al-Askar M, Almas K, Georgios E, Al-Hezaimi K. ISRN Dentistry. 2012;1:1-6 doi:10.5402/2012/762095.

Recibido : 25-10-2012

Aceptado: 19-02-2013 